\title{
Dynamic Time-History Analysis of Steel frame-Composite Steel Plate Shear Wall Structures
}

\author{
Xiaotong PENG ${ }^{1, a}$, Yue TENG ${ }^{1, b}$, Chen $\operatorname{LIN}^{2, c}$, Ye ZHOU ${ }^{1, d}$ \\ 1School of Civil Engineering and Architecture, University of Jinan, Jinan 250022, China \\ ${ }^{2}$ School of Architecture and Landscape Design, Shandong University of Art \& Design, Jinan \\ 250014, China \\ apengxito@163.com, ${ }^{\mathrm{b}} 289521594 @ q q . c o m,{ }^{\mathrm{c}}$ linch77@126.com, ${ }^{\mathrm{d}}$ zhouyejndx@163.com
}

\begin{abstract}
Keywords: steel frame-composite steel shear wall, dynamic, time-history analysis, Bidirectional ground motions, Three-dimensional space model.

Abstract. In order to study the dynamic performance of steel frame-composite steel shear wall structure, a dynamic time-history analysis of a practical hospital buliding was carried out by using FEM software Sap2000. As a comparison, the studies on the building with reinforced concrete shear wall $\mathrm{s}$ and steel plate shear wall were also performed. In the FEM model, the factors such as bidirectional ground motions and three-dimensional space were considered. The results indicate that the steel frame-composite steel shear wall structure has higher strength, ample lateral stiffness and better energy dissipation capacity than traditional structures.
\end{abstract}

\section{Introduction}

The composite steel plate shear wall is a non-stiffened core plate with the concrete covers at two sides, and the three plates are connected together as a sanwich wall by using of bolts. Relevant Experimental research ${ }^{[1]}$ shows that the concrete cover plates could prevent the steel plate from premature buckling, and the bearing capacity of the steel plate is effectively utilized, so the comprehensive performance of the composite steel plate shear wall is better than that of the traditional concrete shear wall and steel plate shear wall; In 2005, Y.L.Guo ${ }^{[2-3]}$ introduced the anti buckling steel plate shear wall, and they found that the concrete slabs could weaken the tension field effect of the steel plate, decrease additional bending moment of frame columns, and improve the energy dissipation capacity efficiently; X.T.Peng put forward the combination of semi-rigid joints and composite shear wall based on previous researches [4] [5] to improve the ductility and energy dissipation of the structure ${ }^{[6-7]}$. At present, studies on hybrid steel plate wall at domestic and abroad are still in initial stage, and relevant research works are mainly focus on two dimensional space model, which is confined to the small proportion of test pieces, so it is difficult to simulate the real stress state of many tall buildings. On the base of the experimental studies on hybrid steel plate shear wall, the 3D space finite element analysis model is established by an example of a hospital building, and two directions of EI-Centro NS earthquake waves are applied at the same time. Through Comparison to anlytical results of the steel frames with traditional steel infll wall and reinforced concrete infill wall, the dynamic behavior evaluation of steel frame-composite steel shear wall(SFCW) is made.

\section{Finite element simulation}

Engineering survey. The example hospital building has 21 stories on the ground and 3 stories underground and the height of standard layer is $2.85 \mathrm{~m}$. The designed structure is the steel frame filled with shear wall, and the shear walls are arranged around the stairs and the elevators which form an inner core tube. Furthermore, the shear walls are arranged in the X,Y directions of the corners taking into account of the effect of torsion.

Finite element model. The representative finite element model of the reinforced concrete plate, the pure steel plate and the composite steel plate shear wall systems is established under same 
conditions of the structural form and the plane size by using the three-dimensional space, as shown in Figure. 1. The model is established by use of the layered shell element ${ }^{[8]}$ of Sap2000-V14, and the elastic-plastic behavior is simulated under the dynamic loading. The internal force of the steel plate is calculated by considering all the nonlinear behavior in the steel plane; Setting the hinge properties at the end of the rod and the position of maximum force to simulate theelastic-plastic behavior of beams, columns and other members. The setting properties are based on FEMA356 (Federal Emergency Management for all kinds of structures of America) ${ }^{[9]}$. The constitutive relation of steel is kinematic hardening model; Shell elements with edge constraint can achieve the deformation coordination; Analysis of nonlinear elastic plastic dynamic response can be calculated by using progressive integral.

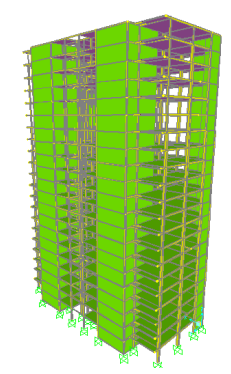

Fig. 1. Finite element model

\section{Time-history analysis under rare earthquake}

Time- history analysis using NS EI-Centro waves, and the peak acceleration is $341.7 \mathrm{~cm} / \mathrm{s}^{2}$, which can be adjusted by the "seismic design code of buildings " ${ }^{[10]}$. Inputting the seismic waves along the X,Y plane for $12 \mathrm{~s}$, the $\mathrm{X}$ direction is the main direction and the $\mathrm{Y}$ direction is the secondary direction, the acceleration is 0.85 times of the main direction.

Story drift angle. The change of the story drift angle under earthquake is shown in Figure. 2. Considering the economy of high-rise building in the low intensity region, the transformation design of the components is performed under the premise of the bearing capacity of the members. However, the displacement angle of the layer is changed suddenly, but it still meet with the displacement angle limit of the seismic design code of buildings ${ }^{[10]}$. The story drift angle of the composite shear wall system is between the plain steel shear wall system and the reinforced concrete shear wall system. The story drift angle reflects the lateral stiffness, so the lateral stiffness of the composite shear wall is greater than that of the pure steel shear wall. While the story drift angle of the reinforced concrete shear wall is smallest with the greatest lateral stiffness.

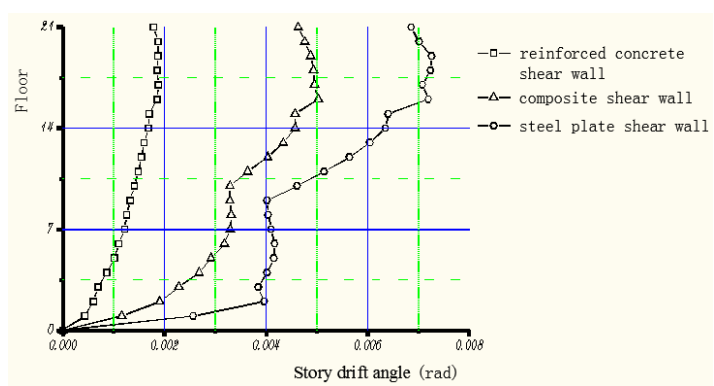

Fig. 2. Story drift angle

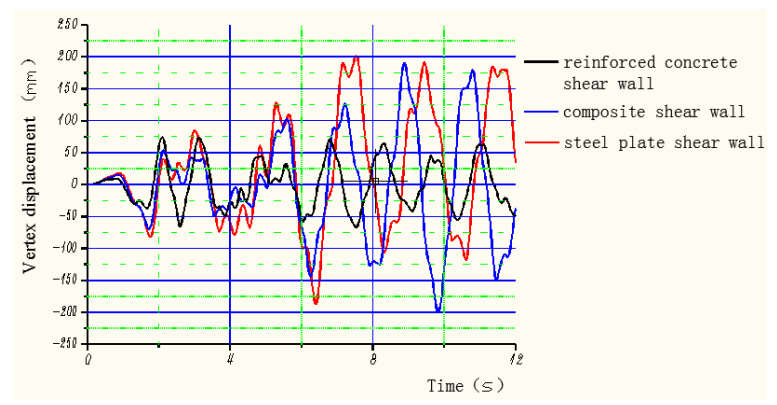

Fig. 3. Vertex displacement

Time-history curves of vertex displacement. Under the rare earthquake, the horizontal displacements of the top of the structures are shown in Figure. 3. The vertex displacement of the reinforced concrete shear wall is changed with eight periods, and the period is relatively short. The peak displacement of the initial earthquake action is $0.75 \mathrm{~mm}$, and the peak changes of the adjacent period is not obvious. The time-history curves of the composite shear wall and the steel plate shear wall are almost the same. The periods of displacement changes are less than that of the concrete shear 
wall system; The period is long and the displacement of the initial earthquake is about $0.5 \mathrm{~mm}$. The peak displacement of the adjacent period appears progressive growth, while the positive and negative vertex displacement changes of the steel shear wall are obvious asymmetry after $8.4 \mathrm{~s}$. It shows that the deformation capacity of the steel plate wall and the composite shear wall are better than the reinforced concrete shear wall. In the late period of earthquake, the steel plate shear wall is in elastic-plastic stage, and the stiffness degradation is serious, resulting in the different change of structural displacement; The composite shear wall has sustained and stable deformation in the elastic-plastic stage by preventing the plate plane from buckling.

Time-history curves of vertex acceleration. The time-history curves of top centroid acceleration under earthquake are shown in Figure.4. Compared to Figure. 4c and Figure. 4d, the distributions on the time axis of the curve in Figure. $4 \mathrm{~b}$ are more dense, inidcating the period is shorter, and period number is more. The difference of the adjacent curve is obvious, showing that the acceleration varies greatly. Compared Figure. $4 \mathrm{~b}$ with Figure. $4 \mathrm{a}$, the peak of the initial earthquake changes in the same way, and the main reason is that concrete structure has high stiffness, the vibration speed get faster after the impact of vibration. Compared to Figure. 4a, the peak changes of the initial acceleration are smaller in Figure. 4c and 4d, and the overall distribution of the curves are sparse. By means of self-deformation, the structure can redistribute the energy to achieve the effect of the energy absorption.

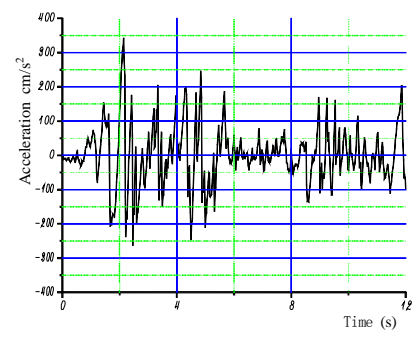

a. EI Centro NS waves

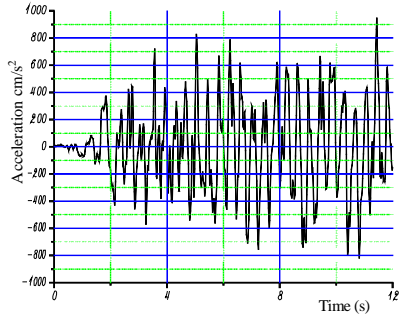

c. Composite shear wall

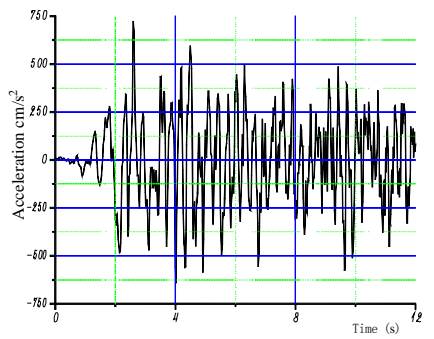

b. Reinforced concrete shear wall

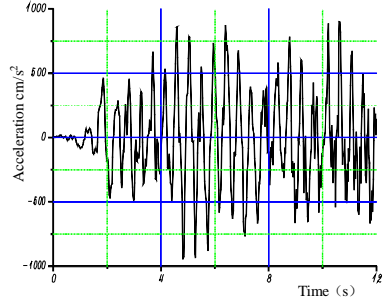

d. Steel plate shear wall

Fig. 4. Time history curves of vertex acceleration

\section{Conclusions}

The dynamic time-history analysis of the buildings under the rare earthquake were carried out by finite element simulation, inwhich the three dimensional space and non-linear behavior were considered. The results show that the story drift angle of the composite shear wall system is between the steel plate shear wall system and the reinforced concrete shear wall system, and the lateral stiffness of composite shear wall is better than steel plate shear wall; The peak displacement curve of the composite shear wall appears progressive growth, and it has good deformation capacity; The composite shear wall has sustained and stable deformation in the elastic-plastic stage, and has better comprehensive performance than the traditional shear wall, which provides a new option for the lateral resistant system. 


\section{Acknowledgements}

The work was sponsored by National Natural Science Foundation of China (51078169) and Key Research and Development Program of Shandong Province (2015GSF122003). The writers gratefully acknowledge the support provided.

\section{References}

[1] Y.Lu, G.Q.Li, F.F.Sun: Experimental Study on Buckling-Restrained Composite Steel Plate Shear Wall with Large Aspect Ratio. Progress in Steel Building Structures. Vol. 11(2009), p.18-27.

[2] Y.L.Guo, Q.L.Dong, M.Zhou: Tests and Analysis on Hysteretic Behavior of Buckling-Restrained Steel Plate Shear Wall. Journal of Building Structures. Vol. 30(2009), p. 31-39.

[3] Y.L.Guo, M.Zhou, Q.L.Dong and X.A.Wang: Experimental study on three types of steel plate shear walls under cyclic loading. Journal of Building Structures. Vol. 32(2011 ), p. 17-29.

[4] X.T. Peng, Q.Gu, C.Lin: Experimental Study on Steel Frame-Reinforced Concrete Infill Wall Structures with Semi-Rigid Joints. China Civil Engineering Journal. Vol. 41(2008), p. 64-69.

[5] X.T. Peng, Q.Gu, C.Lin: Hysteretic Behavior Analysis of Steel Frame Reinforced Concrete Infill Wall Structures with Semi-Rigid Joints. Journal of Building Structures. Vol. 30(2009 ), p. 48-54.

[6] X.T. Peng, Y.Y.Hou, L.Xia: Plastic Analysis on The Semi-Rigid Steel Frame-Composite Steel Plate Shear Wall Structure. Applied Mechanics and Materials. Vol. 351-352 (2013), p. 219- 222.

[7] X.T. Peng,Q.Gu: Seismic Behavior Analysis for Composite Structures of Steel Frame Reinforced Concrete Infill Wall. Structural Design of Tall and Special Buildings. Vol. 22(2013), p. 831-846.

[8] X.Y.Wu,Z.B.Su: Sap2000 V14 of Nonlinear layered shell element. Building structure -Technical Communication. Vol. 22(2013), p. 831-846.

[9] American Society of Civil Engineers: Prestandard and Commentary for The Seismic Rehabilitation of Buildings. (Federal Emergency Management Agency, Washington 2000).

[10] Ministry of Housing and Urban-Rural Construction of the People's Republic of China: GB50011-2010 Seismic Design Code of Buildings. (China Architecture\& Building Press, Beijing 2010). 